\section{The effect of food safety training program on food safety knowledge and practices in hotels' and hospitals' food services}

\author{
Hekmat Al-Akash, ${ }^{1}$ Abdelhakeem Abu \\ Arrah, ${ }^{2}$ Feyza Bhatti, ${ }^{2}$ \\ Roqia Maabreh, ${ }^{3}$ Riham Abu Arrah ${ }^{4}$
}

${ }^{1}$ Applied Science Private University, Amman, Jordan; ${ }^{2}$ Faculty of Business

Management, Girne American

University, North Cyprus; ${ }^{3}$ Paramedic

Department, Prince Al-Hussein Bin

Abdulla II Academy for Civil Protection, Amman, Jordan; ${ }^{4}$ Faculty of Medicine, University of Jordan, Amman, Jordan

\section{Abstract}

Food Safety Knowledge (FSK) among Food Handlers (FHS) in the food services in both hotels and hospitals has a crucial role in food protection and combating against foodborne diseases. The aim is to check the food safety (FS) training program upon FSK in the Jordanian hotels' and hospitals' food services. A pre-test-post-test design was used. A convenience sample of 412 food handlers from randomly selected hotels and hospitals were recruited. Data were collected using 118-questions Food Safety Knowledge Questionnaire (FSKQ); 40- questions tool for FS Practices. A significant improvement in FSK mean scores in the post-test $(85.48 \pm 17.07 / 118$ points corresponded to $72.44 \%$ ) compared with the pretest $(78.50 \pm 13.69 / 118$ points, corresponding to $66.66 \%$ ). The overall mean FSK score was considered to be "moderate" in pre and post-tests. FS Practice level mean was $26.86 \pm 4.38 / 40$ points (67.14\%), regarded as "moderate" in the pre-test and continued to be "moderate" after the training despite a significant increase in the post-test scores $(27.92 \pm 4.45 / 40$ point, corresponded to $69.80 \%, \mathrm{P}=0.000)$. FHS worked in organizations where HACCP principles are implemented, possessed higher FSK and better FS practices. Although continued to be "moderate", FSK and FS Practices among FHS in the Jordanian hotels and hospitals have been significantly improved after the FS Training Program.

\section{Introduction}

Food Safety (FS) is the assurance that food will not cause any harm to the con- sumer when it is prepared or consumed according to its intended use (WHO, 2020). Across the world, it has been estimated that foodborne diseases cause the death of about 2.2 million people annually, where 1.9 million of them are children (WHO, 2017). It has been documented that many foodborne diseases are transmitted by consumers when they are travelling (Ravel et al., 2011) or to patients in hospitals that may worsen their condition, especially if they are immunosuppressed (Muhammad et al., 2020).

Food handlers (FHS) may contaminate food by malpractices linked to a lack of knowledge about the basics of FS, including personal hygiene, proper cooking and storage temperature, and cross-contamination (Hardstaff et al., 2018). This knowledge can be enhanced by training of FHS in safe food handling. A training program of FHS about FS is a widely used strategy to improve FSK (Addo-Tham et al., 2020) and recognized as one of the most critical interventions in preventing foodborne disease outbreaks (WHO, 2020).

In one of the Jordanian studies, Osaili et al. (2017) found that FSK means score among FHS was 56.3/90 and indicated the urgency for FS education and training programs. For the FHS, it was indicated that they must possess a "good" FSK level (above 75\%) and "good" practice level to be able to protect the consumers' meals against foodborne diseases (Osaili et al., 2013). This study responded to these recommendations by planning for the FS training program and evaluating its effect since research in Jordan evaluating the effect of the FS training program upon FSK and FS practices are lacking. Therefore, the aim of this study is to evaluate the effect of the FS training program on FSK and practices at hospitals' and hotels' food services in Jordan.

\section{Research hypotheses}

H1: The FS training program will positively influence FHS' FSK in Hospitals \& Hotels.

H2: Training Program will significantly influence FS Practices in Hospital \& Hotels.

H3: FSK will significantly influence FS Practices by FHS in Hospitals \& Hotels

\section{Materials and methods}

A pretest-Posttest design was used for this study. The population of this study were all FHS from hospitals of different sectors and hotels of different rating in Amman (Jordon). The FHS that were $\geq 18$ years and could read and understand Arabic were recruited through convenience sampling.
Correspondence: Hekmat Al-Akash, Faculty of Nursing, Applied Science Private University, Al Arab St 21, Amman, Jordan.

E-mail: hikmat.akash@yahoo.com

Key words: Food Safety, Training Program, Jordan Hospitals, Jordan Hotels.

Contributions: The authors contributed equally.

Conflict of interest: The authors declare no conflict of interest.

Funding: None.

Availability of data and materials: All data and materials are available within the text.

Received for publication: 15 June 2021.

Accepted for publication: 26 October 2021.

This work is licensed under a Creative Commons Attribution-NonCommercial 4.0 International License (CC BY-NC 4.0).

(C) Copyright: the Author(s), 2022

Licensee PAGEPress, Italy

Italian Journal of Food Safety 2022; 11:9914 doi:10.4081/ijfs.2022.9914

The sample size of 375 was calculated using $\mathrm{G}^{*}$ power 3.1 software (Faul, Erdfelder, Lang, \& Bushner, 2007) with a power of 0.80 , an alpha level of 0.05 , and a medium effect size of 0.3 . Furthermore, $10 \%$ (37) participants were added considering possible dropout of participants, nonresponse, or no return of the questionnaire, making sample size of 412 FHS. An online FS training was developed by the WHO (2006) and administered for the participants by the researchers. A total of 189 FHS, in private hospitals (58 FHS), public hospitals (65 FHS) and hotels (66 FHS) after the baseline data relevant to FSK and practices was gathered. A 3-hours session/day/2weeks (5 days/week) was arranged. Two weeks later, after completion of the program, FSKQ and FS practices questionnaire were re-administered to collect the post-test data. The data were collected online (after signing the informed consent by the participants) using a three-part questionnaire (in the Arabic Language) where part one involved questions about socio demographic characteristic of FHS. Part two was the Food Safety Knowledge Questionnaire (FSKQ). The FSKQ is 118 self-reported questions on FSK that fall under six categories/subscales (Personal Hygiene \& Hand Washing, Health Problems Affecting FS, Food Borne Diseases \& their Symptoms, Cross -Contamination \& Sterilization, Safe Storage, Thawing, Handling, Transport, Catering, Heating/ Reheating, and Food 
Borne Pathogens). Part three was the FS Practices Questionnaire. It included 40 selfreported questions covering three areas; Personal hygiene practices, Cross Contamination Prevention Practices, and Food Handling Practices. Both the FSKQ and the FS practices Questionnaire were validated through national and international studies (Alqurashi et al., 2019; Ayaz, Priyadarshini, \& Jaiswal, 2018; Moreb, Priyadarshini, \& Jaiswal, 2017; Osaili et al., 2013; Osaili et al., 2017). For the reliability of the instruments, an external pilot study on 40 Jordanian FHS was done. Cronbach's $\alpha$ coefficient of internal consistency was used for the reliability of the questionnaires, which was 0.948 for the total FSKQ and 0.734 for the FS Practices. To evaluate the FSK and FS practice level, scores of respondents were calculated by summation of the correct answers (1 point for a correct answer): maximum score is 118 for FSK and 40 for FS Practices (Osaili et al., 2017). Additionally, the score was converted to a percentage for the total score and for each subscale of both the FSK and the FS practice. The score that was lower than $50 \%$ was considered as 'poor', between $50 \%$ to $74 \%$ was considered as 'average', and the score $\geq$ of $75 \%$ was considered as 'good' FSK/FS practice level.

Data were entered and analyzed statistically using Statistical Package for Social Science (SPSS) version 21. For testing research hypotheses, a paired sample t-test was used. Whereas, Correlation Coefficients Analysis was used to test the relationships of FSK and practices and age, experience, and previous exposure to FS training. An independent sample t-test was used to compare FSK and practices based on gender, hotels and hospitals, and hospitals' sectors. A one-way ANOVA was used to compare FHS for FSK and practices according to their education.

The study was approved by the research and ethical committee at Girne American University. Institutional Review Board (IRB) approval was also obtained from two public and private hospitals and two hotels.

\section{Results}

A total of 412 FHS (260 from hospital and 152 from hotels) were recruited, among which 380 responded (245 from hospitals and 135 from hotels), making a response rate of $92 \%$ that were included in the analysis. The demographic characteristics of the FHS can be seen in Table 1.

Analysis of the overall FSK and FS practices showed that they were "moderate". In the analysis of categories, the high- est area of FSK was relevant to "Personal Hygiene and Hand Washing", while the lowest was relevant to "Foodborne Pathogens" in both the pre-test and the posttest. Whereas the highest level of FS practices was also in "Personal Hygiene". Practices relevant to "Food Handling" scored as the lowest, as shown in Table 2 . Table 2 also shows the improvement in the categories of FSK and FS practices in the post-test.

Paired sample t-test was conducted to compare the FHS FSK scores before and after the FS training program. On average, FHS scored higher in the post-test $(\mathrm{M}=85.12, \mathrm{SD}=17.07)$ than in the pre-test $(\mathrm{M}=78.50, \mathrm{SD}=13.69)$. This improvement (the mean difference $=6.62$ ) was statistically significant, [t(350) 8.117, $\mathrm{P}=0.000]$ (Table 3). Results support the first hypothesis (H1: The FS training program significantly influences FHS' FSK in Hospitals \& Hotels).

Similarly, as shown in Table 3, paired sample t-test was conducted to compare the FS Practices scores in the pre-test and in the post-test. There was a significant difference in the scores for the pre-test $(M=26.9$, $\mathrm{SD}=4.38)$ and the post-test $(\mathrm{M}=27.9, \mathrm{SD}=$ 4.45), $[\mathrm{t}(350)=-10.481-, \mathrm{P}=0.000]$. FHS in the post-test possessed statistically significant better practice than in the pre-test. Results support the H2: FS Training Program will significantly influence FS Practices in Hospitals \& Hotels.
Table 3 also shows the t-test values with regards to FHS differences in their FSK/FS Practices based on their categorical sociodemographic variables (gender, area of work: hospital Vs hotel, sector of the hospital: public Vs private, and previous exposure to FS training), and adoption of HACCP. Pearson R correlation (Supplementary Table 1) was done to test that if there a statistically significant relationship between continuous demographic variables (age, years of experience) and FSK/FS practices scores, and Pearson product-moment correlation (Point-Biserial) to test that if there is a statistically significant relationship between "previous training of FS" and FSK scores or FS Practices. Results showed that there are significant statistical mean differences in the total FSK scores with respect to gender $(\mathrm{P}<0.01)$ and to working area (hotel/hospital) $(\mathrm{P}=0.003)$. Whereas, there are no significant statistical mean differences in the total FS Practices scores with respect to the gender $(\mathrm{P}=0.507)$, to working area (hotel/hospital) $(\mathrm{P}=0.518)$, and between hospital sectors $(\mathrm{P}=0.167)$. Results also showed there is no statistically significant correlation between age and FSK score $(\mathrm{R}=0.021, \mathrm{n}=380, \mathrm{P}=0.690)$ or FSK with the years of experience $(\mathrm{R}=0.052$, $\mathrm{n}=380, \mathrm{P}=0.317$ ). Whereas, FS Practices results showed that there is a statistically significant negative association between age and FS Practices score $(\mathrm{R}=-0.114$, $\mathrm{n}=380, \mathrm{P}=0.026$ ), and years of experience

Table 1. Descriptive statistics of sample socio-demographics and settings characteristics $(\mathbf{n}=380)$.

\begin{tabular}{llccc} 
Category & Subcategory & N. & $\%$ & Mean(SD) \\
Gender & Male & 321 & 84.5 & \\
& Female & 59 & 15.5 & $35.0(9.2)$ \\
& Total & 380 & 100 & $11.7(7.6)$ \\
Age (years) & & & & \\
\hline Experience (years) & & & & \\
Educational level & Less than high school & 99 & 26.1 & \\
& High school & 183 & 48.2 & \\
& Diploma & 67 & 17.6 & \\
& BSc & 31 & 8.20 & \\
& Total & 380 & 100 & \\
\hline Previous training & Yes & 30 & 8.00 & \\
& No & 350 & 92.00 & \\
& Total & 380 & 100 & \\
Adopting HACCP & Yes & 2 & 33.33 & \\
& No & 4 & 66.67 & \\
& Total & 6 & 100 & \\
\hline Working Area & Hospital & 245 & 64.5 & \\
(4 hospitals) & Hotel & 135 & 35.5 & 100 \\
(2 hotels) & Total & 380 & 55 & \\
Hospital Sector & Public & 134 & 45 & \\
(2 hospitals) & Private & 111 & 100 & \\
(2 hospitals) & Total & 245 & &
\end{tabular}


and FS Practices score $(\mathrm{R}=-0.106, \mathrm{n}=380$, $\mathrm{P}=0.039$ ). Younger FHS with fewer years of experience were found to have better FS Practices. However, there was no statistically significant correlation between FSK and FS Practices $(\mathrm{R}=0.091, \mathrm{n}=380, \mathrm{P}=0.077)$ in the pre-test scores. Moreover, results show that there is a statistically significant positive association between FSK and FS Practices in the post-test scores $(\mathrm{R}=0.160$, $\mathrm{n}=328, \mathrm{P}=0.002)$. Hence, H3 is accepted that FSK will significantly influence FS
Practices by FHS in Hospitals \& Hotels. Moreover, results show that there was no statistically significant correlation between the previous training and the FSK ( $\mathrm{Rpb}=-$ $0.025-, \mathrm{n}=380, \mathrm{P}=0.625)$ or FS Practices $(\mathrm{Rpb}=0.046, \mathrm{n}=380, \mathrm{P}=0.370)$ in the pretest scores.

Regarding the educational level, oneway ANOVA was conducted (supplementary Tables 2 and 3), which indicates that there is a significant effect of the level of education on the FSK at the $\mathrm{P} \leq 0.05$ level for the four educational levels, $\mathrm{F}(3$, $375)=14.93, \mathrm{P}=0.000$. Post-Hoc comparison using Tukey HSD test indicates that the mean score for the "less than high school educational level" was significantly lower the other categories while there were no significant statistical mean differences at the $\mathrm{P} \leq 0.05$ in FS Practices scores among the educational categories $\mathrm{F}(3,375)=0.485$, $\mathrm{P}=0.693$.

Table 2. Means and percentages of FHS according to their FSK \& FS practices scores on each category.

\begin{tabular}{|c|c|c|c|c|}
\hline \multirow[t]{2}{*}{ FSKQ Subscale } & \multicolumn{2}{|c|}{ Pre-test } & \multicolumn{2}{|c|}{ Post-test } \\
\hline & Mean \pm SD & $\%$ & Mean \pm SD & $\%$ \\
\hline Personal hygiene and hand washing & $18.28 \pm 1.93$ & 87.05 & $19.03 \pm 2.00$ & 90.62 \\
\hline Health problems affecting FS & $7.51 \pm 1.50$ & 83.33 & $7.91 \pm 1.30$ & 87.90 \\
\hline Food borne diseases and their symptoms & $8.26 \pm 2.32$ & 69.16 & $24.00 \pm 6.06$ & 75.00 \\
\hline Cross-contamination and sterilization & $21.38 \pm 6.16$ & 66.88 & $20.82 \pm 6.46$ & 67.16 \\
\hline Safe storage, thawing, handling, transport, catering, heating/ reheating & $19.106 \pm 4.84$ & 61.29 & $6.98 \pm 2.23$ & 53.69 \\
\hline Food borne pathogens & $3.95 \pm 3.05$ & 32.91 & $6.36 \pm 3.94$ & 53.00 \\
\hline Total FSK score & $78.50 \pm 13.69$ & 66.66 & $85.48 \pm 17.07$ & 72.44 \\
\hline \multicolumn{5}{|c|}{ FS practices } \\
\hline Personal hygiene practices & $9.42 \pm 1.71$ & 72.49 & $9.63 \pm 1.52$ & 74.08 \\
\hline Cross-contamination prevention practices & $10.44 \pm 2.67$ & 65.23 & $11.00 \pm 2.00$ & 68.75 \\
\hline Food handling practices & $6.69 \pm 2.29$ & 63.58 & $7.30 \pm 1.90$ & 66.36 \\
\hline Total FS practice score & $26.86 \pm 4.38$ & 67.14 & $27.93 \pm 2.22$ & 69.82 \\
\hline
\end{tabular}

Table 3. T-test analysis of the pre and post FSK and FS Practices according to various variables.

\begin{tabular}{|c|c|c|c|c|}
\hline Variables & Mean \pm SD & Df & T value & P value \\
\hline $\begin{array}{l}\text { FSK } \\
\text { Pre-test (379) } \\
\text { Post-test (328) }\end{array}$ & $\begin{array}{l}78.50 \pm 13.69 \\
85.12 \pm 17.07\end{array}$ & 360 & -7.734 & 0.000 \\
\hline $\begin{array}{l}\text { FSK \& Gender } \\
\text { Male }(320) \\
\text { Female }(59)\end{array}$ & $\begin{array}{l}80.03 \pm 12.96 \\
70.15 \pm 14.61\end{array}$ & 377 & $* 5.271$ & 0.000 \\
\hline $\begin{array}{l}\text { FSK \& Work Settings } \\
\text { Hospitals (245) } \\
\text { Hotel (134) }\end{array}$ & $\begin{array}{l}85.48 \pm 10.54 \\
65.72 \pm 8.63\end{array}$ & 377 & 18.551 & 0.003 \\
\hline $\begin{array}{l}\text { FSK \& Hospital Sectors } \\
\text { Public Hospitals (134) } \\
\text { Private Hospital (111) } \\
\end{array}$ & $\begin{array}{c}86.15 \pm 12.21 \\
84.67 \pm 8.07\end{array}$ & 242 & 5.294 & 0.274 \\
\hline $\begin{array}{l}\text { FSK \& HACCP Adoption } \\
\text { Adopting HACCP } \\
\text { Not Adopting HACCP }\end{array}$ & $\begin{array}{c}89.12 \pm 11.21 \\
72.93 \pm 9.21\end{array}$ & 360 & $* 7.271$ & 0.000 \\
\hline $\begin{array}{l}\text { FS Practices } \\
\text { Pre-test (380) } \\
\text { Post-test (328) } \\
\end{array}$ & $\begin{array}{l}26.86 \pm 4.38 \\
27.92 \pm 4.45\end{array}$ & 350 & -10.48 & 0.000 \\
\hline $\begin{array}{l}\text { FS Practice \& Gender } \\
\text { Male (320) } \\
\text { Female (59) }\end{array}$ & $\begin{array}{l}26.81 \pm 4.30 \\
27.20 \pm 4.78\end{array}$ & 378 & -0.664 & 507 \\
\hline $\begin{array}{l}\text { FS Practice \& Work Settings } \\
\text { Hospitals (245) } \\
\text { Hotel (134) }\end{array}$ & $\begin{array}{l}26.9 \pm 6.33 \\
26.7 \pm 0.15\end{array}$ & 378 & 0.647 & 0.518 \\
\hline $\begin{array}{l}\text { FS Practice \& Hospital Sectors } \\
\text { Public Hospitals (134) } \\
\text { Private Hospital (111) }\end{array}$ & $\begin{array}{l}27.26 \pm 3.15 \\
26.60 \pm 4.27\end{array}$ & 243 & 1.385 & 0.167 \\
\hline
\end{tabular}

*Significant. 


\section{Discussion}

The objective of this study was to evaluate the effectiveness of the FS training program upon the FSK, FS Practices of FHS in both hospitals and hotels in Jordan.

The overall FSK and FS Practices mean score in the pre-test analysis for the current study were found to be "moderate" and below the cut-off point. Compared with the available studies, it was found to be consistent with one of the available studies where most of the participants had moderate FSK (Shokri et al., 2018). The current finding could be attributed to that only $8.2 \%$ of participants were exposed to some form of FS training. This finding also highlighted the necessity for FS training in order to enhance FSK as well as practices, thus, protect consumers' meals against food contamination and foodborne diseases.

In the area of "Personal Hygiene and Hand Washing" and "Knowledge about health problems and conditions", FHS possessed a "good" knowledge in both pre \& post-test and for the control and the intervention groups. Similar conclusions were drawn from recent studies in Jordan (Osaili et al., 2017). A possible explanation for this finding in the current study is that the assessment of FHS in this regard was a selfreported method; overestimation of the knowledge or practice places a possible bias for this result. Accordingly, FHS must be checked for their real adherence to hand hygiene practices through several measures such as randm swab cultures from their hands before or during food processing, cultures of the processed food for presence of FHS-induced pathogens, and observational studies of FHS to confirm their absolute adherence to appropriate hand washing practices.

Knowledge in the area of foodborne diseases and their symptoms was "moderate" in both the pre-test and the post-test results. Insufficient knowledge about the foodborne disease and health problems affecting FS can lead to the inability of FHS to be aware of the seriousness of the issue of food poisoning and other foodborne diseases. Our findings came in line with previous studies (Osaili et al., 2017; ParryHanson et al., 2016). Although the overall score of the subscale of the foodborne diseases and their symptoms is low, respondents correctly responded to well-known symptoms of food poisoning, including nausea, vomiting, abdominal pain, and diarrhoea.

Younger FHS with less experience demonstrated better self-reported practice scores, although there was no variation in the FSK level based on age or years of experience. The age and experience in food handling did not improve the overall FSK assessment outcomes. Mixed findings were found in this regard. Consistently, a supportive conclusion relevant to age and experience was found in one of the studies (Marquitta \& Abbigail, 2015). In many other studies, age, long years of experience with education were found to be positively influencing FSK (Alqurashi et al., 2019; Taha et al., 2019). In Jordan, food workers are noticed to be of lower educational achievements. This notion necessitates the provision of formal training and certification for FHS about FSK and practices. A possible explanation for the finding in our study about age and experience is the improved curriculum at the academic level in the field of food safety and hygiene, younger food hsndlers are holding a diploma or university degree, or younger people are of higher learning abilities so they could have greater benefit from the training than older ones. Further studies are indicated to explain this finding.

FHS with higher educational levels achieved higher knowledge scores in both the pre-test, post-test, and in the intervention group while not for the FS practices. This positive association between the educational level and the FSK was reported in many studies (Hossen et al., 2020; Azanaw et al., 2021). The higher the level of education the FHS possess, the easier it becomes for them to acquire and retain FSK (Farahat et al., 2015).

Before the training program, only $8 \%$ of food handlers were exposed to some form of FS training. So, the association between FSK and previous training couldn't be revealed in this study before the training program. In line with most of the reported conclusions about the importance of FS training (Stangarlin et al., 2016; Habiballah et al., 2018), findings from the current study supported the premise of this importance. Studies investigating barriers to FS training are indicated.

The HACCP FS system is a standardized framework that can ensure a proper implication of food hygienic practices across the food production phases. Its implementation in food services was reported to be of marked impact upon both FSK and FS practices. FHS at the food organizations adopting HACCP were found to be of higher FSK levels than those where HACCP is not implemented as its implementation can positively change FSK and practices (El-Wehedy et al., 2019).

Despite the effort made, the overall FSK remained below the intended and the desired level. Knowledge is often emphasized to have a great role in guiding and directing practices, behaviours, and attitudes of individuals (Shen et al., 2015). Although FSK and FS practices were not changed enough to reach the desired level, self-reported practice scores relevant to FS was associated with improved FSK after training. FHS' training about how to identify FS hazards and implement good practices regarding FS is essential in order to ensure the safety and quality of the foodstuff (Azanaw et al., 2021). However, this assumption has been contradicted as the success of training programs that rely only on providing the information is doubtful as significant changes of improper practices in food handling are not usually achieved (Akabanda et al., 2017). Based on this fact, auditing and observation of FHS during their food handling is still indicated to confirm the transferability of their knowledge into real and safe practices.

In the current study, the limitations include the test/retest bias from the repeated administration of the instrument, the duration of the program was limited to 2 weeks; randomization was not possible as many hotels and hospitals declined the approval to conduct the study and administer the training program, and decreased responses in the post-test (dropout of participants).

The study revealed several recommendations. Such as, further training is required in the areas where FSK levels were low. Moreover, further studies are indicated using various approaches such as observational studies to check the transferability of the knowledge into practice, and studies investigating barriers to involvement of FHS in FS training are indicated. Also, the adoption of HACCP as a standardized FS approach to ensure the adherence to standardized FS and studies investigating barriers toward HACCP implementation is recommended.

\section{Conclusions}

FHS of food services in hospitals and hotels were found to have a moderate FSK and practices prior to the FS training program administration. The administered training program had significantly improved the FSK, FS practices of FHS. Male gender, those with higher educational levels, and who are working in hospitals compared to hotels were found to have higher levels of FSK. Younger FHS with shorter experience were found to have better practice level.

\section{References}

Addo-Tham R, Appiah-Brempong E, 
Vampere H, Acquah-Gyan E, Gyimah Akwasi, A, 2020. Knowledge on food safety and food-handling practices of street food vendors in Ejisu-Juaben Municipality of Ghana. Adv Public Health 2020:4579573.

Akabanda F, Hlortsi E, Owusu-Kwarteng J, 2017. Food safety knowledge, attitudes and practices of institutional food-handlers in Ghana. BMC Public Health 17:1-9.

Alqurashi N, Priyadarshini A, Jaiswal A, 2019. Evaluating Food Safety Knowledge and Practices among Foodservice Staff in Al Madinah Hospitals, Saudi Arabia. Safety 5:9.

Ayaz W, Priyadarshini A, Jaiswal A, 2018. Food Safety Knowledge and Practices among Saudi Mothers. Foods 7:7.

Azanaw J, Dagne H, Andualem Z, Adane T, 2021. Food safety knowledge, attitude, and practice of college students, Ethiopia 2019: A Cross-Sectional Study. Bio Med Res Int 2021.

El-Wehedy S, Darwish W, Tharwat A, Hafez A, 2019. Hygienic status of meat served at hospitals and its improvement after HACCP implementation. Jpn J Vet Res 67:61-73.

Faul F, Erdfelder E, Lang A, \& Bushner A, 2007. G*Power: a flexible statistical power analysis program for the social, behavioral, and biomedical sciences. Behav Res Methods 39:175-191.

Habiballah M, Al-Shakhsheer F, AlAbabneh M, 2018. Foodservices Employees' Food Handling Practices in Irbid City, Jordan. J Tour Hosp Manag 5:81-89.

Hardstaff J, Clough H, Lutje V, McIntyre M, Harris J, Garner P, O’Brien S, 2018. Foodborne and food-handler norovirus outbreaks: A systematic review. Foodborne Pathog Dis 15:589-597.

Hossen M, Ferdaus M, Hasan M, Lina NN, Das AK, Barman SK, Paul DK, Roy RK., 2020. Food safety knowledge, attitudes and practices of street food vendors in Jashore region, Bangladesh. J Food Sci Technol 41:226-39.

Marquitta W, Abbigail M, 2015. Food safety knowledge of foodservice workers at a university campus by education level, experience, and food safety training. Food Control, 50:259-264.

Mohammed H, Ahmed S, Ahmed A, 2020. Food safety knowledge, attitudes and practices (KAP) of the nutrition staff in three Sudanese hospitals. JSSFN 13:1016.

Moreb N, Priyadarshini A, Jaiswal A, 2017. Knowledge of food safety and food handling practices amongst food handlers in the Republic of Ireland. Food Control, 80:341-49.

Osaili T, Jamous D, Obeidat B, Bawadi H, Tayyem R, Subih H, 2013. Food safety knowledge among food workers in restaurants in Jordan. Food Control 31:145-50.

Osaili T, Obeidat B, AlNabulsi A, 2017. Food Safety knowledge among foodservice staff in hospitals in Jordan. Food Control 78:279-85.

Parry-Hanson K, Ofosu D, Aboagye E, Tano-Debrah K, 2016. Food safety knowledge, attitudes and self-reported practices of food handlers in institutional foodservice in Accra, Ghana. Food Control 69:324-30.

Ravel A, Nesbitt A, Marshall B, Sittler N, Pollati F, 2011. Description and burden of travel-related cases caused by enteropathogens reported in a Canadian com- munity. Travel Med 18:8-19.

Shen M, Hu M, Sun Z, 2015. Assessment of school-based quasi-experimental nutrition and food safety health education for primary school students in two poverty-stricken counties of west China. PLoS One 10:e0145090.

Shokri R, Hashemi M, Jorvand R, Hajiveisi H, Shamsi A, Far H, Rezaei S, 2018. A survey on the knowledge and attitudes of Dehloran health network personnel about food safety and health. J Adv Environ Health Res 6:27-33.

Stangarlin L, Medeirds L, Serafim A, Bertini R, Medeirds C, Hecktheuer L, 2016. Good hygiene practices in hospital nutrition services: the view of internal and external auditors. Food Sci Technol, 36:461-67.

Taha T, Osaili T, Saddal N, Al-Nabulsi A, Ayyash M, Obaid R, 2019. Food safety knowledge among food handlers in food service establishments in United Arab Emirates. Food Control 110: 106968.

World Health Organization, 2006. Five Keys to safe food manual: WHO department of food safety, zoonosis and foodborne disease. [Retrieved 2 April, 2019] http:/www.who.int/foodsafety/ publications/consumer/manual_keys.pd $\mathrm{f}$

World Health Organization, 2017. [Retrieved 3 May, 2021] https://www.who.int/news-room/factsheets/detail/food-safety

World Health Organization, 2020. COVID19 and Food Safety: Guidance for Food Businesses: interim guidance. [Retrieved 10 September, 2020], WHO2019-nCoV-Food Safety-2020.1eng.pdf. 